\title{
What to ask when sexual abuse is suspected
}

\author{
J M LEVENTHAL,$*$ A BENTOVIM,$\dagger$ A ELTON,$\dagger$ M TRANTER,$\dagger$ AND L READ $\dagger$
}

${ }^{*}$ Department of Pediatrics and the Child Study Center, Yale University School of Medicine, New Haven, Connecticut, United States of America, and †Department of Psychological Medicine, Hospital for Sick Children, Great Ormond Street, London

Over the past few years there has been a considerable increase in the recognition and reporting of the sexual abuse of children. ${ }^{12}$ Although the child often reveals the abuse to an adult such as a parent or teacher, physicians who provide medical care to children (including paediatricians and general practitioners) are often the first professionals to suspect that abuse has occurred. Much has been written about the possible presentations of sexually abused children from vaginal discharge to symptoms less obviously related to sexual abuse such as abdominal pain, encopresis, or running away from home. ${ }^{34}$ There are an increasing number of reports of the variety of physical findings ${ }^{5-8}$ and on the appropriate laboratory investigations. ${ }^{5910}$ Despite this increase in attention to the problem, however, little has been written about how the physician should raise the possible diagnosis of sexual abuse with either the parent or child.

\section{Raising the possibility of sexual abuse}

In a doctor's surgery concern about sexual abuse can be raised in two different ways. Firstly, the parent (usually the mother) or occasionally an older child or adolescent raises the issue with the doctor. The parent is seeking help to discover what has happened and to protect the child. For example, a mother may mention that she is worried about sexual abuse because last week her 7 year old daughter said that her uncle 'had been rude with her.' The mother does not think that her daughter is making this up, but cannot be sure. By raising the issue she is giving implicit permission for the doctor to talk to the child about the event and carry out an appropriate medical examination.

By contrast, the issue can be raised if the doctor, during the evaluation of the child, becomes suspicious about the possibility of sexual abuse. In such circumstances he will be faced with several questions. Could the child have been sexually abused, or could there be some other explanation for his findings? What is the best way to raise the issue with the parent(s) and child, keeping in mind that the parents might be offended and angry? If direct questions are asked and the child denies that anything has happened, has the diagnosis of sexual abuse been excluded? How much questioning is necessary before being reasonably certain that nothing has happened (given that it may be impossible to exclude completely such a diagnosis)?

There are at least three different circumstances when there is no direct allegation but when the doctor may consider the diagnosis of sexual abuse and have to ask questions of the parent and child. These are:

(i) when a child has a complaint that might be directly related to the possibility of sexual abuse, such as a girl with a vaginal discharge;

(ii) when a child has a complaint that is not directly related to the possibility of sexual abuse, such as abdominal pain or encopresis;

(iii) when a child has no complaint but an incidental finding, such as an enlarged hymenal ring, makes the doctor suspicious.

A COMPLAINT RELATED TO THE POSSIBILITY OF SEXUAL ABUSE

The first is perhaps the easiest occasion on which to raise the question of sexual abuse. Direct questions may be part of the history taking before examining the child: 'Do you have any idea how your daughter got this vaginal discharge?' 'Could anyone have touched her in the vaginal area where she is having this problem?' When a preadolescent child is being examined with the mother in the room, it might be appropriate to ask the mother's permission to talk to the child: 'I'd like to ask your daughter some questions about the same topic, as well.' During the examination of the child's vulva, the doctor might ask, 'What do you call this part of your body? What comes from there?' If the child has difficulty answering, the mother may be asked what the family calls that part of the body. The doctor may then ask about touching: 'Has anyone touched you there?' If the child denies that anyone has touched her, the doctor may ask about who helps her in the bath: 'Who washes you there? Do you wash yourself there 
now or does someone help you?' 'Does anyone ever put ointments or medications there?' 'Does anyone else ever touch you there?' Watching the way that the mother or child responds may be as helpful as the actual responses to the questions. For example, the doctor may be less concerned about the possibility of sexual abuse if the child seems relaxed for the setting and answers questions appropriately (this may include embarrassment or amusement, or both, at the questions about names of parts of the body or amazement at questions about who touches her private parts). In contrast, more worrying kinds of responses might include obvious changes in mood after specific questions (such as looking sad, frightened, or 'frozen'); more difficulties than expected for age in answering certain questions; or a string of 'No' responses that seem to shut out the interviewer or to be overinsistent denials rather than statements that nothing has happened.

At this point, experts in interviewing young children suspected of being sexually abused, might try a more indirect approach by using hypothetical questions to find out if abuse has occurred. ${ }^{11}$ Although we described this technique, we believe that it should be used sparingly if at all, except by experts, because of the difficulty in interpreting the child's responses. Examples of such questions (to the mother) would be; 'If someone had touched her there, who would she tell?' and to the girl, 'If someone had touched you, who would you tell?' 'If you were touched, would it be a nice touch or a rude touch?' 'Would it have hurt a lot or a little?' 'Would it be more rude if you were touched by someone who was not part of your family or was in your family, like your father, sister, or brother?' This style of questioning may be helpful when asking about difficult or sensitive topics when it may be considerably more difficult for the child to say what has happened than to deny it. By not asking direct questions, the child has the opportunity to indicate what he or she may do (or have done). For instance, a child who has been abused may respond with more details than would be expected for a child of that age who has not been abused, who might say that she doesn't really know whether it would hurt 'a lot or a little.'

Finally, a few direct questions may help the child to indicate what has happened. 'Has anyone touched you there?' 'Does your daddy or your sister or your brother ever touch you there?' Of course, it is important to know who is in the family and household and who else looks after the child.

If the answers to such questions do not raise concern about the possibility of sexual abuse and if the medical examination is negative it would be reasonable to assume that the child has not been abused. If, however, either the responses or the medical examination raise concern, then arrangements should be made for a case conference to be convened and for the child to be interviewed more extensively by a clinician with special expertise in the diagnosis and treatment of sexual abuse. If the parent asks why you are concerned about sexual abuse, it is easy to explain that because of all the recent publicity about the problem, it is medically indicated to ask such questions.

\section{A COMPLAINT NOT DIRECTLY RELATED TO THE POSSIBILITY OF SEXUAL ABUSE}

Under these circumstances the doctor may be asked to evaluate a child with a psychosomatic complaint such as abdominal pain, anorexia, or a psychiatric symptom such as attempted suicide. After taking a complete history and examining the child it may be appropriate to interview him or her alone. How should one go about introducing the topic of sexual abuse? During the interview the doctor may explain that sometimes problems like the one that the child has are not due to physical abnormalities, but rather to tensions or worries, particularly secret ones, and that there are lots of kinds of worries that children have that may cause such symptoms. After this kind of statement the doctor may mention various kinds of worries and secrets including the possibility that someone has been abusing the child.

Of course, the extent of the exploration would depend on the results of the examination so far. If it is clear from the history that the abdominal pain is due to recent identifiable stresses in the child's life, such as difficulties at school or parental discord, then one would be less likely to explore extensively the possibility of sexual abuse. On the other hand, if the cause of the symptom is not clear, then it would be reasonable to spend a portion of the interview asking about sexual abuse: 'Sometimes children like you who are having difficulties with soiling have been hurt or touched in a bad way on the bottom; could that ever have happened to you?' Or, 'Sometimes children who have pain like yours are worried because someone has been touching them in a way that they don't like, but they don't know how to stop it or who to tell about it. Has that been happening to you?' 'Even if it has happened, most children find it very difficult to talk about. Have you been worried about that?' Because it is often difficult for the child both to talk about the abuse (if it has happened) and to find the right words to describe the events, a denial should be considered in the same way as denials about other painful topics; the questions may have to be repeated in future, and the doctor should be willing to listen to the child if he or she makes oblique references to the topic. 
A SUSPICION OF SEXUAL ABUSE BASED ON A ROUTINE PHYSICAL EXAMINATION

The most difficult situation occurs when an abnormality is detected on a routine examination that raises the possibility of sexual abuse. That the child and parent have not come to the doctor with a specific complaint makes the situation especially difficult. There is always the temptation to ignore or belittle the finding and not to mention it, as might occur after detecting a soft heart murmur and not mentioning it to save the parents from worrying. A more reasonable approach, especially if one is uncertain about the abnormality, is to refer the child to a doctor with experience in examining sexually abused children. In discussing the physical finding, a direct approach often works best: 'I've noticed what looks like an abnormality at the opening of your child's vagina. I'm not $100 \%$ sure, but I think there is some scar tissue there. Do you know if anyone has been touching or hurting your daughter down there? I may need to do some further investigations. I would like to talk to your daughter for a few minutes alone, and then I think that it would be best if she was examined by someone with more expertise than me.' The types of questions to the child that follow would be similar to those presented above.

\section{The interview with the child and further action}

Because the child and parent have ostensibly come to the doctor for an evaluation of a physical problem or for a check up, the questions about the possibility of sexual abuse should be asked with care and after a rapport has been established. Although it is not unreasonable to ask the child questions with the parent in the room, there may be times when the child may not be able to say what has happened in the adult's presence. The child may be worried that his mother might blame him for what happened, or he may be worried because the parent in the room is the abuser. If the child seems hesitant in the parent's presence or if the parent always answers for the child, it may be helpful to see the child alone for a few minutes. Children who are at least 6 or 7 years old might be seen alone from the beginning of the interview.

There are times when it is better not to ask further questions. A child may become so upset that it would be wise to stop the interview and indicate to the child that she appears very upset by the questions and that it is difficult to talk about such topics. To make clear to the child that the doctor recognises her pain, it may be helpful to add, 'I'm worried that you were touched in a way that may have been rude, and I would like to arrange for you to talk to someone else about what happened.' In such a case an inpatient evaluation may be helpful, and this should be dicussed with the parent before mentioning it to the child.

In some circumstances the gender of the doctor may influence whether the child feels comfortable enough to be able to answer questions about the abuse. As most offenders are male, there may be times when a male doctor may be more successful interviewing a child in the presence of a female colleague; likewise, pairing a female doctor with a male colleague may sometimes be helpful.

RAISING THE POSSIBILITY OF SEXUAL ABUSE

The initial question about the possibility of sexual abuse is more difficult to ask in theory than in reality. Although parents may be surprised, alarmed, or angered, they have certainly heard about such problems and do not find the question unreasonable. The major difficulty for the doctor is then to know when a denial, particularly by a child, truly indicates that nothing has happened as opposed to a false statement because of previous threats or worries about revealing the secret. ${ }^{12}$ As in the assessment of other clinical problems, the information provided by the child has to be amalgamated with other data, including the child's behavioural symptoms (the teacher reports that the child has been repeatedly touching other children in the genital region); the medical history (recurrent episodes of vaginal discharge); the family history; the physical examination; and the laboratory investigations. If the hymenal ring looks slightly enlarged, but the remainder of the data do not give cause for concern, it may be best to re-examine the child in several months and in the meantime assume that the child has not been abused. On the other hand, if Neisseria gonorrhoeae is cultured from a vaginal discharge sexual abuse has occurred regardless of any statement that nothing has happened.

In proceeding with the initial evaluation, the physician should be prepared to make several important decisions:

WHO SHOULD BE TOLD ABOUT THE SUSPICION OF SEXUAL ABUSE?

\section{Telling the parent}

If information from the interview or physical examination indicates that the child has been sexually abused, it is best to inform the parent of the findings. If, however, the doctor is concerned about the possibility of sexual abuse but cannot make a clinical diagnosis then he or she has to decide how much to tell the parent. Usually the doctor outlines the concerns and the recommendations for further evaluation; on rare occasions, however, it would not be in the child's best interests to indicate the specific 
concerns ${ }^{13}$ For example if the doctor is worried that the accompanying parent is involved in the abuse, he might withhold the details from the parent for fear that he or she may pressure the child not to talk further. Under such circumstances, the doctor may say: 'Your daughter appears to have some worries, and I'd like to arrange for her to talk with someone in more detail about these.'

\section{Informing the social services department}

In the United States the laws of each state require that the doctor report cases of suspected sexual abuse, not just confirmed cases, to the state's protective service agency. In the United Kingdom reporting of child maltreatment is not compulsory. The guidelines, Child abuse-working together, from the Department of Health and Social Security, however, ${ }^{14}$ recommend that cases of suspected sexual abuse should be reported to the local social services department or the National Society for the Prevention of Cruelty to Children (NSPCC), and through these agencies to the police so that there can be a thorough investigation of the allegation. Without such a referral it is usually impossible to carry out an adequate evaluation or to ensure protection of the child. As part of this evaluation the social services, the NSPCC, or the police may ask for assistance from a variety of specialists (paediatrician, police surgeon, child psychiatrist, child psychologist, and so on). At some time, either during the initial investigation or shortly thereafter, a case conference should be held, and the findings discussed by all who have been involved in the investigation and who have responsibility for providing services to the child and family.

IF SEXUAL ABUSE IS SUSPECTED, SHOULD THE CHILD BE ALLOWED TO GO HOME?

The decision to allow a child to go home should be made jointly with the social worker (sometimes only after an initial case conference) and will depend on the certainty of the diagnosis, the safety of the current living arrangements, and the ability of the parent to protect the child. For instance, if there is a strong suspicion that abuse has occurred from the child's evidence alone, but the mother seems to believe her child and understand the concerns, and if the child will not be living with the alleged perpetrator until the matter is resolved, then it seems appropriate to allow the child to go home. There are, however, three risks to allowing a child who is being abused to return home. The child may be threatened and told not to say anything else about the abuse, subsequently retracting her or his statement; the child may continue to be sexually abused; or the child may be physically abused for revealing the secret. Obviously, all three of these possibilities are highly dangerous for the child. If the doctors decide that it is not safe for the child to return home he or she may stay with a relative, be placed in an emergency foster home, or be admitted to hospital until a more appropriate arrangement can be made. If the parents disagree with placing the child away from home, social services may need to take emergency legal action (in the United Kingdom a place of safety order, or in the United States an order of temporary custody) and arrange temporary accommodation to ensure the child's safety.

\section{SHOULD THE ALLEGED PERPETRATOR BE INTERVIEWED} AS WELL BY THE PHYSICIAN?

When an accusation is made about a person, he or she is usually interviewed by a police officer (sometimes accompanied by a social worker). Representatives from the police and social services departments have the statutory duty to investigate cases of suspected sexual abuse. ${ }^{14}$ Occasionally the alleged perpetrator may want to speak to the doctor who made the initial evaluation. In such circumstances it is helpful for the doctor to consult the police and social services about when best to conduct the interview.

Doctors who are experts in the management of cases of abuse and sexual abuse may participate in joint interviews with social services not only to clarify the medical findings, but also to explore possible ways in which abuse may have occurred. These are often difficult interviews: the alleged perpetrator may be angry or threatening, or he may be convincing in his statements of affection for the child and denial of sexual abuse. In these latter circumstances the professionals may wonder whether the information from the child's interview or physical examination was overinterpreted or misunderstood.

SHOULD THE SIBLINGS BE INVESTIGATED?

Because siblings may have been sexually abused as well, examinations of these children should be arranged as soon as possible. Social services may arrange these and ask that the physician examine the siblings for signs of physical and sexual abuse.

\section{Do children lie about the occurrence of sexual abuse?}

Often the diagnosis of sexual abuse is clear, but sometimes it is difficult to sort out exactly what happened to the child. It is in these circumstances that it is important for the doctor to believe what the child says and help to protect him or her during the initial stages of the evaluation. There are, however, occasions when it is best to be cautious about the 
diagnosis, although most experts feel that these occasions are rare.

Suspicions that are based on the history may turn out to be unfounded because either a thorough evaluation fails to confirm the suspicion or the specific allegation by an adult or child is found to be fictitious. An example of the first type of case is an evaluation that finds no evidence of sexual abuse in a 3 year old child who is referred because of unusual sexual play in a nursery school. An example of the second type of case is an evaluation that finds no evidence of sexual abuse in a 5 year old who has alleged to have been abused on an access visit by his natural father. These cases may include lies, as well as misunderstandings or confused interpretations of the behaviour of others. ${ }^{15}$

Only a few reports have investigated the incidence of either type of unfounded accusation. In one study doctors found no evidence of sexual abuse in 4 of 64 children $(6 \%)$ aged from 2 to 12 years who were evaluated for suspected sexual abuse for six months in the casualty department of a large urban hospital in $1973 .{ }^{16}$ In a more recent study the senior author reviewed the records of 83 consecutive children all less than 7 years old who were referred to a hospital for suspected sexual abuse. ${ }^{17}$ In $14 \%$ there was no evidence of sexual abuse; these children often were either very young (less than 3 years old) so it was difficult to obtain information from the interviews, or were siblings of sexually abused children. Jones $e t$ al reviewed cases that were referred to a local child protection agency: of 439 referrals with adequate information to permit an independent review, $22 \%$ were considered to be unsubstantiated. ${ }^{15}$ This figure is likely to be higher than that seen at a hospital because the agency received referrals from a variety of sources including 'neighbours, relatives, child minders, and professionals.' 15

As part of the same study, the authors examined the incidence of fictitious allegations. Of the 439 referrals to the local child protection agency, 34 $(8 \%)$ were classified by the investigators as fictitious, 26 by adults ( $6 \%$ of all the cases) and eight by children $(2 \%)$. Fictitious allegations were noted even more infrequently at the regional child abuse centre, the Kempe Center at the University of Colorado. From 1983 to 1985 there were 21 cases (3\% of 717 ) compared with 696 cases of convincing accounts (no mention is made of cases that were not substantiated). Of these 21 accounts, five were made by children, nine by adults, and seven by both. In the five cases in which a child made the allegation, four of the children had been sexually abused in the past and were suffering from an untreated post traumatic stress disorder. In the cases in which an adult made the allegation, all were women, six had been abused, neglected, or deprived or both in the past, and five had considerable emotional disturbances; in seven of the cases, there also was a custody or visitation dispute. Finally, all the cases in which the allegation came from both the child and adult involved 'bitter' custody or visitation disputes; in addition, all the mothers concerned were psychiatrically disturbed, three of them having been sexually abused at about the same age as the index child.

Thus fictitious allegations of sexual abuse are sometimes made, although rarely by children. When such allegations are made there are often unusual circumstances. More commonly occurring cases seem to be those in which the suspicion of sexual abuse is not substantiated. As professionals become more vigilant about the manifestations of sexual abuse, the incidence of these unsubstantiated cases may increase because children with milder and more non-specific symptoms will be referred for evaluation.

Experts on interviewing young children about sexual abuse have discussed approaches to distinguishing true allegations from fictitious ones. ${ }^{18} 19$ Important factors are the child's attitude when telling them about what happened, the description of the details of the events (including the sexualo actions, whether the child was hurt, who was present, and where the events occurred), the description of any threats to maintain secrecy, and the response to telling the doctor. Other reports have noted that it is particularly difficult to assess the accuracy of an allegation when parents are fighting over custody of the child. ${ }^{2021}$ In such circumstances one parent may be convinced that abuse has occurred and distort the child's memories of contact to induce the child to accuse the other parent of sexual abuse. The occurrence of fictitious allegations is much higher in these cases than in other clinical presentations. ${ }^{2021}$

If the diagnosis of sexual abuse is to be made, doctors who care for children should be aware not only of the presenting symptoms and signs, but also of how to ask about the possibility of sexual abuse, how to listen to the child's responses, how to integrate the preliminary findings, and how to make referrals to the appropriate child protection agency. While it is true that making the diagnosis of sexual abuse can have tremendous implications for the child and family, not making the diagnosis can leave a child in a dangerous situation of continuing abuse.

\footnotetext{
References

' Anonymous. Ill-treatment in children. [Editorial]. Lancet $1987 ; \mathbf{i}: 367-8$.
} 
${ }^{2}$ Creighton SJ. Child abuse in 1985: initial findings from NSPCC register research. Research Briefing No 7. London: NSPCC, 1986.

${ }^{3}$ Krugman RD. Recognition of sexual abuse in children. Pediatrics in Review 1986;8:25-30.

${ }^{4}$ Hunter RS, Kilstrom N, Loda F. Sexually abused children: identifying masked presentations in a medical setting. Child Abuse Negl 1985;9:17-26.

5 Heger A. Response child sexual abuse: a medical view. Los Angeles: United Way and Children's Institute International, 1985 .

${ }^{6}$ Hobbs CJ, Wynne JM. Buggery in childhood - a common syndrome of child abuse. Lancet 1986;ii:792-6.

7 Enos WF, Conrath TB, Byer JC. Forensic evaluation of the sexually abused child. Pediatrics 1986;78:385-8.

${ }^{8}$ McCauley J, Gorman RL, Guzinski G. Toluidene blue in the detection of perineal lacerations in pediatric and adolescent sexual abuse victims. Pediatrics 1986;78:1039-43.

9 Hammerschlag MR, Cummings M, Doraiswamy B, Cox P, McCormak WM. Nonspecific vaginitis following sexual abuse in children. Pediatrics 1985;75:1028-31.

${ }^{10}$ Hammerschlag MR, Doraiswamy B, Alexander ER, Cox P, Price W, Gleyzer A. Are recto-genital chlamydial infections a marker of sexual abuse in children? Pediatr Infect Dis 1984;3:100-4.

11 Vizard E. Interviewing young, sexually abused children assessment techniques. Family Law 1987;17:28-33.

12 Summit RC. The child sexual abuse accommodation syndrome. Child Abuse Negl 1983;7:177-93.

\section{Commentary}

\section{R E I ROBERTS}

\section{Manchester}

Much of what Hobbs and Wynne say is uncontroversial and merely describes in detail the accepted practice succinctly laid down in the current Department of Health and Social Security (DHSS) guidelines for dealing with child sexual abuse-a multidisciplinary investigation should take place and the child should be talked to and examined in a sensitive manner in a clinical setting. It is the specific aspects of the medical examination and the conclusions that they draw which are extremely controversial: they state that $40 \%$ to $50 \%$ of boys and girls have anal abnormalities.

Four women doctors in the Greater Manchester area doing examinations at the request of police, social workers, the National Society for the Prevention of Cruelty to Children (NSPCC), and paediatricians saw approximately 500 children in 1986 (Robinson, Jacobs and Welliver, personal communication). They always take a full history and talk to the child and carer about medical problems as well as any history of abuse. A history of possible anal interference is obtained from a much smaller proportion of these children than from the cases reported by Hobbs and Wynne, and in only a
${ }^{13}$ Racusin RJ, Felsman JK. Reporting child abuse: the ethical obligations to inform parents. J Am Acad Child Psychiatry 1986;25:485-9.

${ }^{14}$ Department of Health and Social Security. Child abuse working together. London: HMSO, 1986.

15 Jones DPH, McGraw JM. Reliable and fictitious accounts of sexual abuse in children. Journal of Interpersonal Violence 1987;2:25-45.

16 Peters JJ. Children who are victims of sexual assault and the psychology of offenders. Am J Psychother 1976;30:398-421.

17 Leventhal JM, Hamilton J, Rekedal S, Tebano-Micci A, Eyster C. Results of a diagnostic interview in young children suspected of being sexually abused. Submitted for publication

${ }^{18}$ Faller KC. Is the child victim of sexual abuse telling the truth? Child Abuse Negl 1984;8:473-81.

19 de Young M. A conceptual model for judging the truthfulness of a young child's allegation of sexual abuse. Am J Orthopsychiatry 1986;56:550-9.

${ }^{20}$ Green $\mathrm{AH}$. True and false allegations of sexual abuse in child custody disputes. J Am Acad Child Psychiatry 1986;25:449-56.

21 Benedek EP, Schetky DH. Allegation of sexual abuse in child custody and visitation disputes. In: Schetky DH, Benedek EP, eds. Emerging issues in child psychiatry and the law. New York: Brunner/Mazel, 1985:145-56.

Correspondence to Dr J M Leventhal, Yale University School of Medicine, 333 Cedar St, New Haven, Connecticut 06510, USA.

Received 22 June 1987 handful has definite medical evidence in the anal area been found. Precise figures are not yet available but they are in the process of being prepared for publication. Police surgeons throughout the country have made the same observations and the subject was exhaustively discussed at the recent Association of Police Surgeons of Great Britain annual meeting. None of the experienced police surgeons, many of them having the Diploma in Medical Jurisprudence and most of them experienced general practitioners with considerable experience of children, has found anything more than an extremely small proportion of children with anal evidence of sexual abuse.

Hobbs and Wynne say that they can tell merely by inspecting an anus that it is lax. They use the subjective and misleading test of so called 'reflex dilatation' on skin traction on the buttocks to make a definitive diagnosis of 'sexual abuse.' The opening of the anus on inspection-which should be done without traction by gently placing the hands on the cheeks of the buttocks - is variable, misleading, and present in a number of other conditions including chronic constipation, thread-worms, and anal thrush 